\title{
Card game as a pedagogical tool for numeracy skills development
}

\author{
Parmjit Singh', Teoh Sian Hoon ${ }^{2}$, Akmal Md Nasir ${ }^{3}$, Adlan Md Ramly ${ }^{4}$, Syazwani Md Rasid ${ }^{5}$, Chew \\ Cheng Meng ${ }^{6}$ \\ 1,2,3,4,5Faculty of Education, Universiti Teknologi MARA, Malaysia \\ ${ }^{6}$ School of Educational Studies, Universiti Sains Malaysia, Malaysia
}

\begin{abstract}
Article Info
Article history:

Received May 6, 2020

Revised Mar 11, 2021

Accepted Apr 17, 2021

Keywords:

Card matching

Educational games

Mathematics education

Numeracy skills

ABSTRACT

Given the hypothesis that card games form a strong tool capable of shaping the aforementioned interest, this study has developed a card game called Math Zap as a pedagogical tool for numeracy skills development in the context of mental computation. It is geared towards investigating the efficacy of this Math Zap card game, in facilitating the development of numeracy skills amongst learners, and their attitude towards using it as a pedagogical tool. A mix method approach using an experimental and descriptive design was taken and tested amongst 34 primary school students aged 12 to 13 . From the results of the study, it is found that the Math Zap card game is a highly effective learning tool in so far as the enhancement of students' numeracy computation skills in the areas of fractions, percentages and decimals are concerned. This is evidenced by a statistical significant pre-post test score increment. Furthermore, students were rather positive and receptive towards the game, further substantiating the claim of it being a useful pedagogical tool.
\end{abstract}

This is an open access article under the CC BY-SA license.

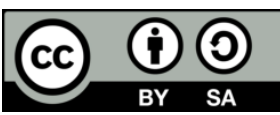

\section{Corresponding Author:}

Parmjit Singh

Faculty of Education

Universiti Teknologi MARA

Puncak Alam Campus, Selangor 42300 Selangor, Malaysia

Email: parmj378@uitm.edu.my

\section{INTRODUCTION}

One of the prime focus points of mathematics educators around the world concerns inculcating an interest and a deep desire to learn the subject amongst students, and to have the passion mathematical learning. Teaching methods that focus on hands on experiences and real-life problems enable learners to better grasp mathematical knowledge from a practical standpoint. The root cause of poor performance in mathematics is usually nestled in their experiential learning, where the subject is often treated as dull and boring [1]-[3]. Such a barren view creates the domino effect that tends to demotivate them [4], [5] and scupper their interest [6], which leads to poor performance as such. The main contention here is that, creating a positive attitude towards math is an important first step in shaping students' success in the subject. In the quest for mathematical knowledge and mastery of concepts, learners who actively participate in the process of finding solutions to problems form an instrumental part of the teaching environment.

Numerous studies and research conducted over the decades depict a declining trend in the efficiency of numeracy skills concepts in terms of speed and accuracy amongst both primary and secondary school students. The efficiency in mentally computing problems related to basic operation skills such as 64+99, $20-3,1 / 2+1 / 2$; recognition of operators and relationship between fractions, decimals and percentage such as 
recognition between $1 / 2+1 / 2$ and $1,0.25$ and $1 / 4,0.05$ and $5 \%$ showcase a declining trend over the years. This phenomenon is a global one, and has been observed in UK [7], Turkey [8], Canada [9], [10], Northern Ireland [11] and Malaysia [12], [13]. In this article, we investigate the effectiveness of using a card game called Math Zap amongst Primary school students in enhancing numeracy efficiency and their attitude towards using it as a pedagogical tool.

\section{LITERATURE REVIEW}

This section highlights related studies to the variables of study, namely the importance of mathematical learning, fundamentals of numeracy development and game-based learning as a pedagogical tool in the provision of foundational information for the study.

\subsection{Importance of early math and numeracy}

The ultimate goal in mathematical learning concerns the development of a deeper lifelong knowledge amongst students that caters for changes. Studies over the years [7]-[13] depict that students are struggling with the very fundamentals of mathematical learning. Maths learnt in the early years, and numeracy being an overall knowledge of numbers are foundational mathematics concepts utilized by most learners in their day to day lives through play and daily interactions which include skills such as basic counting, comparisons and the ability to differentiate, recognizing shapes and positions, and problem solving [14], [15]. Future math ability is closely linked to the development of these early math abilities and there is evidence of this in several longitudinal studies [16]-[18]. The ability of a student to grasp mathematical concepts in the future is very much dependent on how strong their foundation is, based on what they would have learnt during their early years of schooling. In a study by Harris and Petersen [14], a correlation was found, such that students who underperformed in later grades happened to possess poor mathematical skills in their early schooling days. Without these basics, students were bound to struggle later on, with more complex mathematical concepts. Hence, it is clear that cultivating mathematical and numeracy skills are in essence, stepping stones towards futuristic excellence in this domain, and following so, the optimum solution would certainly be to ensure such maths learning and intervention takes place at an early entry level in schools.

\subsection{Development of numeracy skills via intervention}

The building blocks as the scope of the study relates to the meaning of numbers, the representation of numbers, the connection between them and calculations that are essential in the development of numeracy skills. These skills, sometimes interchangeably called number sense, can be described as a learner's overall knowledge of numbers and operations combined with the capability of using this understanding in adaptable ways in the development of techniques in the solution of complex problems and forming mathematical judgements [19], [20].

With the passage of time, studies have depicted various intervention programs in enhancing numeracy skills. In a study by Papadakis, et al. [21], the impact of two varying digital technologies in the understanding of numbers amongst students were assessed in the early childhood stage itself. Three hundred and sixty-five children aged approximately five years old participated in this experimental design study, where there was active participation amongst the learners. The findings depicted that both the technological devices outperformed the traditional group in the comprehension of number knowledge. In another study by Kathleen, et al. [22] investigating the effects of taped problem (TP) intervention relating to the acquiring of addition-fact skills at the outset in a first-grade general education classroom was looked into. It was gathered that students who are actively engaged in repeated practice with quick recall and response of additional facts could draw on their reasoning abilities in the learning of concepts and other skills. Yet, in another study by Heirdsfield [23], the findings revealed that the teaching of early mathematical concepts and techniques was not only crucial in the development of mental computation strategies, but was instrumental in the development of higher order thinking skills, analysis and a deeper understanding of numbers and operations. According Aubrey and Godfrey [16, p.1], among 118 students in 5th grade (11-12-year-olds), the relationship between mental computation and mathematical reasoning was explored. Their findings show:

(There) is a significant positive correlation between mental computation and mathematical reasoning. It is noteworthy that rather than exposing students to familiar classical problems, students need to be enabled to deal with exceptional/non-routine problems, and especially young children should be encouraged to do mental computing in order for developing both skills. 
It is thereby suggested that instruction intervention in mental computation and estimation can support the development of reasoning in children. The results of the studies [16], [21]-[23], showed that intervention programs and practicing mental strategies had a notable effect on students' paradigms towards their mental methodologies and number sense abilities. All these activities as suggested by the researchers are based on active participation of learners [24]. Highlighted that children learn best when they are engaged in meaningful and logical activities, as there is a deeper learning experience they can relate to, where they can interact socially and are given clarity as to a specific goal. This is where the concept of learning with play comes into action.

\subsection{Game based learning}

Promoting numerical fluency in mental computation via active participation is of paramount significance for enhancing mathematical learning amongst students. Learning through experience and interaction lays the foundation of the learning through games theory. Experiential learning through games provides an avenue for students to play around in a safe environment and gain knowledge by practicing and interacting socially with their play mates and the environment. Having understood this, educators endorse the importance of active student involvement in mathematical learning rather than just following the teacher's direction [25], [26]. Constructivists support this notion where the paradigm for learning is one that involves active construction [26], where knowledge is constructed based on prior active learning. Knowledge can never just stay in a homeostasis. Realizing this, it is best for children to be the authors of their own knowledge. To do so, elements such as sharing, discussing, reflecting and negotiating are of utmost importance. Thus, new educational methods need to be exploited for these pedagogical advantages. This is where the concept of learning with play comes into action.

There have been numerous schools of thought that view education as an organic process that cannot be forced through drilling. One of such views come from the field of Neurolinguistics that emphasized the fact that children need to be allowed to play as it is not a process opposite to education, but a younger learning process [27]. This contests the common notion that playing is detrimental to educational growth. This has propelled educational researches to explore and assimilate games into the learning process. There is a common view that games are developed mainly for promoting the learners' effective usage or application in education through different levels of engagement [28]. Given that the mere mention of the word 'game' posits the notion of fun, what better way can there be to invoke learning amongst children? A plethora of educators and researchers have begun to acknowledge the importance of Game-Based Learning. In essence, game-based learning uses certain gaming principles in a real-life context of learning to increase its appeal to students [29]. Some of the advantages of game-based learning includes its ability to include both individualistic and social efficacy to the players; containing multiple elements and structures that can be embedded in learning; motivating students through the sense of belonging to the learning process; and reducing mental strains during the learning process [30], [31]. The contention is that by using games as a medium, the pedagogical issues raised earlier could be resolved in a fun and interesting manner. There is a valid hypothesis that instructional games increase students' learning performance since the level of motivation is considered one of the performance factors [29], [30], [32].

While video games may be addictive and disruptive [33], [34], there is a noble idea of using card games as a method of learning. Studies showed that instructional games such as card games supplement the learning process, and students who engage in such games attain better math grades and develop a more positive attitude towards mathematics [35], [36]. Furthermore, card games kill two birds with one stone: as on one hand, it strengthens family and friendship bonds since everyone comes together to play the game; and in the process, children reap the benefits of acquiring mathematical knowledge amidst the fun [37]. Card games have several resulting benefits, from sociological to developmental aspects [37] because children build mental computation skills during play time in addition to imbibing key values such as sportsmanship and honesty [38]. As Shaffe, et al. [39] elucidated, these games merge the different methods of knowing, doing, being and caring.

There is a scarcity of research findings pertaining to the impact of educational card games to boost students' math learning, especially in the context of numeracy skills development. In this study, the research team firstly outlined the phases involved in the development of the Math Zap card game as a learning tool for enhancing numeracy skills via mental computation in the areas of whole numbers, fractions, decimals and percentages for lower secondary school students (ages 12-13). Secondly, it examined the impact of the card game as a pedagogical tool for numeracy skills development. Thirdly, it evaluated students' attitude towards the Math Zap card game as a pedagogical tool for numeracy development. 


\section{RESEARCH METHOD}

This section details the methodology employed for the study in terms of the design, samples involved, instrumentation and analysis procedures.

\subsection{Research design}

This two phase study employed two different research designs namely Research and Development model ( $\mathrm{R}$ and $\mathrm{D}$ model) and an experimental design. In the first phase, the researchers utilized the research and development model of Gall, et al. [40] for the development of the Math Zap card game. This model was used with a systematic process in place, which involved field testing and evaluation until the product met its specific predetermined criteria. This Math Zap Card Game was developed, validated and evaluated based on the five-phase development process (Figure 1).

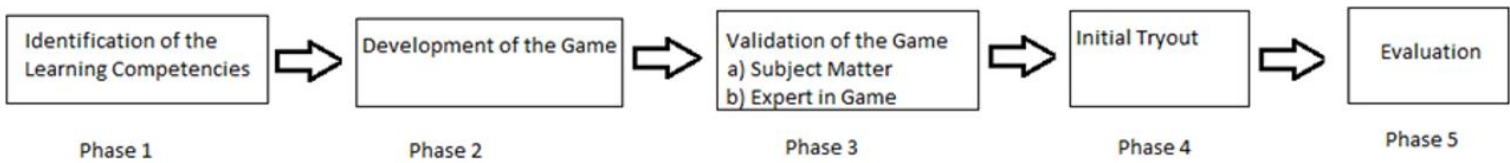

Figure 1. Development framework

Phase 1-3 marked the development stage of the Math Zap card game, while phase 4-5 concerned the assessment of the effectiveness and evaluation of the card game developed. The description of the phases is:

Phase 1. The identification of the learning competencies content which include Fractions, Percentages, Decimals, Whole Numbers \& Roman Numerals.

Phase 2. Design, development and pre-implementation of the Math Zap card game was included in this phase. It also included selection of content for each topic, content level, card design, colour contrast \& size, and rules of the game.

Phase 3. Three school maths teachers and two gaming experts were selected to conduct an evaluation of the card game based on the learning competencies identified.

Phase 4. The research team utilized the pretest-posttest one group experimental design amongst 16 students from grade 6 to test the effectiveness of the card game.

Phase 5. Five main criterias were used for the evaluation of the card game: 1) Goals and objectives; 2) Design; 3) Components and organization; 4) Playability and playfulness; and 5) Usefulness.

\subsection{Description of card game and its rules}

The invention, called, "Math Zap" is a card game that enhances the development of numeracy skills in enhancing mental computation.

Number of Players : 2 to 6 players

Content

: 1) Numeral's recognition; 2) Fundamentals of four mental operator skills; 3) Operators and relationship between fractions, decimals and percentages; 4) Roman numerals; 5) Whole numbers; and 6) Relationship between Numerals and Roman Numerals.

Skills developed : The ability to match, higher alertness, longer attention, increased mental and visual speed, and the ability to provide verbal responses.

Aim of the game : The main aim of this game is to get all the cards in the pack, and if it doesn't happen, the game goes on.

Start of play $\quad:$ All players should have with them an equal number of cards, and the dealing player has to ensure this. The cards are to be placed facing down and no one is allowed to have a look at their decks. To get the ball rolling, the player seated on the right-side of the dealer begins the game by promptly putting a card in the middle of the table, facing up.

The draw : The cycle of continually placing cards after cards on the top to form a pile in the middle continues until a match or pair is found, for instance: 5 and $5 ; 2+2$ and $4 ; 1 / 2+1 / 2$ and 1 (Figure 2).

Melding : The first player to place his hands-on top of the pile and shout "Zap" gets them all.

Forfeit : The main aim of this game is to get all the cards in the pack, and if it doesn't happen, the game goes on. When the player shouts "Zap" at the wrong time, his/her turn gets forfeited and a penalty is incurred.

Game ends : The first player to get all the cards is declared the winner. 
A design-based research consideration as suggested by Barab and Squire [41] was also utilised for this research. This improves the focus of the experimental design process in its totality as Schoenfeld [42] elucidated that 'the products of well conducted design experiments are improved interventions and improved understandings of the processes that result in their productiveness'. The detailed considerations of this study are depicted in Table 1.

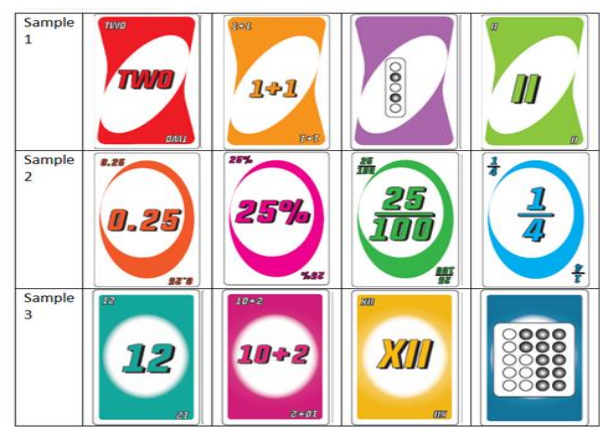

Figure 2. Sample pictures of Math Zap

Table 1. Design-based considerations in Math Zap research

\begin{tabular}{ll}
\hline Design-based considerations & \multicolumn{1}{c}{ Details } \\
\hline Location of research & $\begin{array}{l}\text { Conducted in a classroom environment where the actual teaching and learning process took place } \\
\text { in two different schools }\end{array}$ \\
Complexity of variables & $\begin{array}{l}\text { Variables included Math Content Computation (Fractions, Percentages, Decimals, Whole } \\
\text { Numbers \& Roman Numerals), Attitude towards Math Zap (learning, enjoyment and interaction) }\end{array}$ \\
The effect of playing the card games on their Math Content and Attitude towards it.
\end{tabular}

In the second phase, a one-group pretest-posttest quasi experimental design (Figure 3) was employed in which the Mental Computation Test was administered before and after the treatment to examine the effectiveness of the card games in enhancing students' numeracy skills. The researchers acknowledge of the limitation of this design of no control group that are prone to threats of internal validity. This design was chosen because of some ethical issues related to sample selection. The selected administrator of the school insisted that all groups be allowed to play the card game and insisted that no student be deprived of this activity. Thus, this inhibited the selection of a control group. Due to the circumstances, the researchers acknowledged confounding factor possibilities which might inhibit the ability for causal inference.

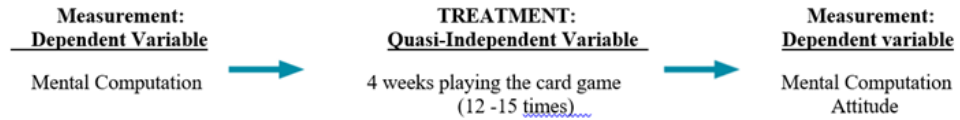

Figure 3. The one-group quasi experimental design

\subsection{Samples of study}

Thirty-four Secondary One students, between ages 12 to 13, as an intact class was randomly selected using a block sampling from five classes from a public school in a district in Selangor, Malaysia. These students have formally learnt the topics (Fractions, Percentages, Decimals \& Whole Numbers) based on their school curriculum since grade 5. For the qualitative data, a sample of five teachers who were involved in facilitating the students playing of the Math Zap card game were interviewed in seeking their views regarding the game. 


\subsection{Instrumentation}

Two instruments were used in assessing the effectiveness of the card game in developing numeracy skills and a positive attitude towards playing the card game. The first instrument, Mental Computation Test, focused on reinforcing basic math skills in terms of identifying numbers, comparing numerical values which require accurate observation, and quick reactions. This test was adapted from McIntosh, et al. [43] where it comprised 40 items of four strands in the framework: Decimals, Fractions, Percentages and Roman Numerals. Each item was scored based on a correct and incorrect response, capitulating a maximum score of 40. The second instrument, adapted from Gutierrez [35] was utilized to evaluate the students' view of the developed Math Zap as a learning tool. This questionnaire which comprised 25 items utilized a five-point rating scale based on five criteria, namely: 1) Goals and objectives; 2) Design; 3) Components and organization; 4) Playability and playfulness; and 5) Usefulness. However, for this paper, due to space constraint, only three criteria are discussed, namely goals and objectives, playability and playfulness, and usefulness are displayed.

\subsection{Procedure}

Prior to the experiment, a 20-minute pre-test was performed to evaluate the numeracy proficiency amongst students via the Mental Computation Test. Following the pre-test, the 34 samples were randomly divided into groups of 4 or 5 where they played the game for approximately 12-15 times each in the duration of 4 weeks. Some students played it more often than others due to attendance constraints. After the 4 weeks, a post-test (comprising of questions that were similar to the pre-test) as well as an attitude questionnaire were administered with a time duration of 30 minutes set for its completion. As the mental computation test was aimed at the assessment of students' mental prowess, 30 seconds were given for each item and they were given only an answer sheet to write their answers on. A Power Point Presentation was used to show the particular question on screen and the following question was posed after a lapse of 30 seconds, thereby giving no room for the students to use written computation to solve the problems.

\subsection{Validity and reliability}

In establishing the content validity of the mental computation test, the suggestions of 3 experienced school teachers were taken. The subject content, percentage of items in each area, and the cognitive processes involved were incorporated into a table of specification. Recommendations that had been made for an improvement of the instrument were considered. On the other hand, to establish the reliability coefficient analysis, a test-retest reliability methodology was utilized on a group of 16 (intact class) secondary one student (ages 13) from a different school.

As shown in Table 2, the scores for both tests $(\mathrm{M}=12.32, \mathrm{SD}=5.26)$ and re-tests $(\mathrm{M}=12.58$, $\mathrm{SD}=5.17$ ) were highly similar on both testing occasions. It resulted in a high Pearson Product Moment Correlation coefficient of .917 (Table 3) indicating the mental computation test as a reliable tool for measuring mental computation of numeracy skills.

Table 2. Descriptive analysis of test-retest of mental

\begin{tabular}{llll}
\multicolumn{4}{c}{ computation test } \\
\hline & $\mathrm{N}$ & Mean & SD \\
\hline Test & 16 & 12.32 & 5.26 \\
Re-test & 16 & 12.58 & 5.17 \\
\hline Max score: 40 & &
\end{tabular}

Table 3. Test-retest correlations coefficient

\begin{tabular}{ccc} 
& & Re-test \\
\hline Test & Pearson correlation & $.917(* *)$ \\
& Sig. (2-tailed) & .000 \\
& $\mathrm{~N}$ & 15 \\
\hline
\end{tabular}

Similar processes of ascertaining the content validity of the questionnaire were conducted, where it was given to three experts in establishing content validity. For testing the reliability of the instrument, Cronbach's Alpha analysis was utilized. The result of the reliability coefficient for the overall instrument was 0.8615 , hence indicating that it was a reliable tool for measurement. From the validity and reliability process of both the instruments used in the study, one can surmise that the instrument used was valid for the data collection purposes for this study.

\section{RESULTS}

This section details the findings of study, namely the mental computation test comprising the numeracy skills and students' perceived views on the card games. This first result, as shown in Table 4, depicts the pretest-post test One Sample experimental design to test the effectiveness of the Math Zap card game in the content area of Fractions, Percentages, Decimals, Whole Numbers and Roman Numerals. The 
table shows that the overall mean scores of both the pretest and the posttest are $12.06(\mathrm{SD}=6.25)$ and 32.47 $(\mathrm{SD}=5.79)$ respectively, from a maximum score of 40 . An increase of 20.41 was observed from pretest to post test. It is interesting to note an increase of approximately $170 \%$ in the scores after playing the game. The $\mathrm{t}$-test analysis indicates a significant difference [ $\mathrm{t}(33)=-20.41, \mathrm{p}<.05]$ in the jump between the pre-test and post-test scores. The finding also indicates a significant difference in all learning strands at the 0.05 level. The highest significant increment in scores are in the strand of Whole numbers to Roman Numerals [ $\mathrm{t}(33)=$ $-17.813, \mathrm{p}<.05]$ and followed by Roman Numerals to Whole numbers [t $(33)=-15.812, \mathrm{p}<.05]$ and Percentage to Fraction [t $(33)=-13.034, \mathrm{p}<.05]$. These findings indicate that students playing the Math Zap card game had a positive impact on their numeracy skills development proficiency.

Table 4. Paired sample T-test analysis across strands (max score=40)

\begin{tabular}{|c|c|c|c|c|c|c|c|}
\hline \multirow{2}{*}{ Learning strands } & \multicolumn{2}{|c|}{ Mean } & \multirow{2}{*}{$\begin{array}{c}\text { Mean } \\
\text { difference }\end{array}$} & \multirow{2}{*}{ Rank } & \multirow{2}{*}{$\mathrm{t}$} & \multirow{2}{*}{ df } & \multirow{2}{*}{ Sig (2 tailed) } \\
\hline & Pre-test & Post-test & & & & & \\
\hline Decimal to percentage & $2.41(\mathrm{SD}=1.46)$ & $4.79(\mathrm{SD}=0.69)$ & -2.38 & 6 & -11.063 & 33 & .000 \\
\hline Decimal to fraction & $0.88(\mathrm{SD}=1.43)$ & $3.53(\mathrm{SD}=1.08)$ & -2.65 & 5 & -12.569 & 33 & .000 \\
\hline Percentage to decimal & $4.29(\mathrm{SD}=1.61)$ & $4.79(\mathrm{SD}=0.69)$ & -.50 & 8 & -2.632 & 33 & .013 \\
\hline Percentage to fraction & $0.71(\mathrm{SD}=1.19)$ & $3.50(\mathrm{SD}=1.13)$ & -2.79 & 3 & -13.034 & 33 & .000 \\
\hline Fraction to decimal & $0.85(\mathrm{SD}=1.18)$ & $3.62(\mathrm{SD}=1.28)$ & -2.76 & 4 & -11.994 & 33 & .000 \\
\hline Fraction to percentage & $1.94(\mathrm{SD}=1.76)$ & $4.09(\mathrm{SD}=1.03)$ & -2.15 & 7 & -8.835 & 33 & .000 \\
\hline $\begin{array}{l}\text { Roman numerals to } \\
\text { whole numbers }\end{array}$ & $0.65(\mathrm{SD}=0.77)$ & $4.06(\mathrm{SD}=1.04)$ & -3.41 & 2 & -15.812 & 33 & .000 \\
\hline $\begin{array}{l}\text { Whole numbers to } \\
\text { roman numerals }\end{array}$ & $0.32(\mathrm{SD}=0.98)$ & $4.09(\mathrm{SD}=1.08)$ & -3.77 & 1 & -17.813 & 33 & .000 \\
\hline Overall & $12.06(\mathrm{SD}=6.25)$ & $32.47(\mathrm{SD}=5.79)$ & -20.41 & & -19.970 & 33 & .000 \\
\hline
\end{tabular}

\subsection{Evaluation of the Math Zap card game}

The evaluation of the Math Zap card game was undertaken by 34 students involved in the experimental design based on the dimensions of: 1) Goals and objectives; 2) Design; 3) Components and organization; 4) Playability and playfulness; and 5) Usefulness. As discussed in the methodology section, only three criteria will be discussed here due to space constraint. Table 5 to Table 9 illustrate the descriptive findings based on students' perceived view. The descriptive findings were based on frequency counts, measure of central location, namely mean and the interpretation of these descriptive measures. The interpretation of the mean scores were based on the following descriptors as shown in Table 5.

Table 5. Mean score interpretation descriptors

\begin{tabular}{cc}
\hline Mean scores & Interpretation \\
\hline Less than 2.75 (less than 55$)$ & Very unsatisfactory \\
2.75 to $3.22(55$ to 64$)$ & Unsatisfactory \\
3.23 to $3.72(65$ to 74$)$ & Satisfactory \\
3.73 to $4.47(75$ to 89$)$ & Very satisfactory \\
4.48 to $5.00(90$ to 100$)$ & Outstanding \\
\hline
\end{tabular}

The first criteria as shown in Table 6 is based on the goals and objectives of the Math Zap Card game. All the items except item 3 (mean=3.95, $\mathrm{SD}=.66$ ) obtained a mean score of more than 4.0 depicting a very satisfactory perceived view for each item. In fact, item 6 "The card game helps with my recall of concepts/terms" obtained a high mean score of 4.59 with a standard deviation of 0.61 indicating an outstanding view by students on their revision of the concepts involved namely decimals, percentages and fractions. The overall mean score of $4.22(\mathrm{SD}=.62)$ for the criteria of goals and objectives of the Math Zap Card Game depicts a very satisfactory evaluation view by the students.

The fourth criteria (as the second and third were not discussed) relates to the playability and playfulness of the Math Zap Card Game that comprised four items (Table 7). All the items in this criterion depicted a mean score of more than 4.20 which can be interpreted as very satisfactory by the students. The highest mean score was obtained for item 17 "The game provides opportunity for healthy competition and cooperation" and item 20 "Playing the game was fun" with scores of $4.50(\mathrm{SD}=.66)$ and $4.39(\mathrm{SD}=.92)$ respectively. The overall mean score of $4.34(\mathrm{SD}=.65)$ depicts a very satisfactory evaluation by students towards the playability and playfulness of the Math Zap card game.

Table 8 shows the final criteria that comprising five items relate to the evaluation of students on the usefulness of the Math Zap card game. All the items in these criteria obtained high means scores of 4.32 (item 23) and above. The highest mean scores are obtained for item 21 (mean=4.76, SD=.43), item 25 
(mean=4.56, $\mathrm{SD}=.55)$ and item 22 (mean=4.50, $\mathrm{SD}=.66)$ indicating an outstanding evaluation by students. The overall mean score of $4.52(\mathrm{SD}=.75)$ can be interpreted as outstanding by students on their evaluation towards the usefulness of the Math Zap card game.

Table 6. Goals and objectives evaluation of the Math Zap card game $(\mathrm{N}=34)$

\begin{tabular}{|c|c|c|c|c|c|c|c|c|c|}
\hline & \multirow{2}{*}{ Goals and objectives } & \multicolumn{5}{|c|}{ Frequency } & \multirow{2}{*}{ Mean } & \multirow{2}{*}{ SD } & \multirow{2}{*}{ Interpretation } \\
\hline & & 5 & 4 & 3 & 2 & 1 & & & \\
\hline 1 & The purpose and rationale for the game are fully explained. & 9 & 18 & 6 & 1 & 0 & 4.03 & .76 & Very satisfactory \\
\hline 2 & The goals and objectives of the game are clearly defined. & 10 & 20 & 4 & 0 & 0 & 4.18 & 63 & Very satisfactory \\
\hline 3 & The game was thought provoking. & 3 & 25 & 4 & 2 & 0 & 3.95 & .66 & Very satisfactory \\
\hline 4 & The game encouraged student interaction. & 20 & 8 & 6 & 0 & 0 & 4.41 & .78 & Very satisfactory \\
\hline 5 & The game promoted discussion of key topics. & 13 & 17 & 4 & 0 & 0 & 4.26 & .67 & Very satisfactory \\
\hline \multirow[t]{2}{*}{6} & The card game helps with my recall of concepts/terms. & 22 & 10 & 2 & 0 & 0 & 4.59 & .61 & Outstanding \\
\hline & Average mean & & & & & & 4.22 & .62 & Very satisfactory \\
\hline
\end{tabular}

Table 7. Playability and playfulness evaluation of the Math Zap card game (N=34)

\begin{tabular}{|c|c|c|c|c|c|c|c|c|c|}
\hline \multirow{2}{*}{\multicolumn{2}{|c|}{ Playability and playfulness }} & \multicolumn{5}{|c|}{ Frequency } & \multirow{2}{*}{ Mean } & \multirow{2}{*}{ SD } & \multirow{2}{*}{ Interpretation } \\
\hline & & 5 & 4 & 3 & 2 & 1 & & & \\
\hline 17 & $\begin{array}{l}\text { The game provides opportunity for healthy competition } \\
\text { and cooperation. }\end{array}$ & 20 & 12 & 2 & 0 & 0 & 4.50 & .66 & Outstanding \\
\hline 18 & $\begin{array}{l}\text { The rules of the game provide players with equal } \\
\text { conditions for a fair play. }\end{array}$ & 13 & 16 & 4 & 1 & 0 & 4.24 & .70 & Very satisfactory \\
\hline 19 & $\begin{array}{l}\text { The rules of the game provide a set of options for } \\
\text { flexibility in making decisions when playing the game. }\end{array}$ & 10 & 22 & 1 & 2 & 0 & 4.23 & .55 & Very satisfactory \\
\hline 20 & $\begin{array}{l}\text { Playing the game was fun. } \\
\text { Average mean }\end{array}$ & 21 & 7 & 5 & 1 & 0 & $\begin{array}{l}4.39 \\
4.34\end{array}$ & $\begin{array}{l}.92 \\
.65\end{array}$ & $\begin{array}{l}\text { Very satisfactory } \\
\text { Very satisfactory }\end{array}$ \\
\hline
\end{tabular}

Table 8. Usefulness evaluation of the Math Zap card game $(\mathrm{N}=34)$

\begin{tabular}{|c|c|c|c|c|c|c|c|c|c|}
\hline \multirow{2}{*}{\multicolumn{2}{|c|}{ Playability and playfulness }} & \multicolumn{5}{|c|}{ Frequency } & \multirow{2}{*}{ Mean } & \multirow{2}{*}{ SD } & \multirow{2}{*}{ Interpretation } \\
\hline & & 5 & 4 & 3 & 2 & 1 & & & \\
\hline 22 & $\begin{array}{l}\text { The game encouraged the players to dig deeper } \\
\text { into the subject matter. }\end{array}$ & 18 & 14 & 1 & 1 & 0 & 4.50 & .56 & Outstanding \\
\hline 23 & Playing the game is a productive use of time. & 14 & 17 & 3 & 0 & 0 & 4.32 & .64 & Very satisfactory \\
\hline 24 & $\begin{array}{l}\text { Playing the game helped me establish better } \\
\text { relationships with the members of the group. }\end{array}$ & 19 & 12 & 2 & 1 & 0 & 4.47 & .66 & Very satisfactory \\
\hline
\end{tabular}

Table 9 shows the overall descriptive evaluation of the Math Zap card game based on the five criteria. The highest mean score was obtained for the criteria of "usefulness" (mean=4.52, SD=.75) followed by "Playability and Playfulness" and "Card Design" (mean=4.23, SD=.75). On the other hand, the lowest mean score was recorded for the criteria of "Components and Organization" with a mean score of 4.01 $(\mathrm{SD}=.66)$. Based on the overall score of $4.52(\mathrm{SD}=.75)$, one can surmise that students involved in the study have an outstanding view towards the Math Zap card game as an education tool. Thus, one can conclude that this Math Zap card game is an important education tool in developing student's computation concepts development in Fractions, Decimals, Percentages, Whole Numbers and Roman Numerals.

Table 9. Overall descriptive evaluation of Math Zap

\begin{tabular}{|c|c|c|c|c|}
\hline & Evaluation in terms of: & Mean & SD & Interpretation \\
\hline 1. & Goals and objectives & 4.22 & .62 & Very satisfactory \\
\hline 2. & Card design* & 4.23 & .75 & Very satisfactory \\
\hline 3. & Components and organization* & 4.01 & .66 & Very satisfactory \\
\hline 4. & Playability and playfulness & 4.34 & .65 & Very satisfactory \\
\hline \multirow[t]{2}{*}{5.} & Usefulness & 4.52 & .75 & Outstanding \\
\hline & Overall mean & 4.28 & .55 & Very satisfactory \\
\hline
\end{tabular}

\subsection{Qualitative data from the interviews}

This section details the qualitative findings of the study based on the focus group interviews conducted with the five school teachers that were involved in the study. 


\subsubsection{Interviews with teachers}

This section details the focus group interview with the five teachers involved in the study. A sample of 5 teachers who were involved in the facilitation of the Math Zap card game were interviewed in seeking their views regarding the game. They were initially briefed on the goals, rules and procedures of the game. These five teachers got the chance to play the game among themselves (between 10 to 12 times) and were also involved in playing with their students. These teachers were interviewed using a focus group interview method to share their findings (R: Researcher; T: Teachers).

Students in this study thoroughly enjoyed the card game simply because it was captivating and engaging. In the midst of competing, there was a sense of joy, as they grappled with numerous challenges, including trying to outwit each other, and finally celebrating their victory upon winning.

$\mathrm{T} 1$ : I can see students having great fun playing the game ... by the way I enjoyed it too .... seeing them zapping, stumping the table, standing on their feet, and on many occasions expressing their joy by shouting "Hooray!" or "I won!"

T2 : The students, especially the boys, when they win quite often bragged to their friends and also to me... as I was seated in a distance, saying, "Teacher, I won."

The most apparent form of the 'joy of learning' is intrinsic motivation which leads to wanting more of $i t$. When students are involved and engaged in playing, they are more motivated to learn. Nurturing joy in this manner is immensely rewarding and leads to a very pleasant environment, given that naturally, when students love what they do, they participate more in it.

T1 : I also noticed that not only did they find interest in the game but also wanted to experience winning as they repeatedly participated in the game.

$\mathrm{T} 3:$ :... and the best part, I don't have to force them.... they just want to continue to play this game.

T4 : ... even the losers wished to continue with the game.

Children learn best through action rather than instruction, which then leads to first-hand experience. The constructivist philosophy behind pedagogical approaches in mathematical learning places an emphasis on meaning and view the learner's role as one to construct knowledge. When children enjoy learning, the thirst and motivation for further knowledge comes naturally without force, and acquisition of it in this manner is extremely important for kick starting early development of numeracy skills.

$\mathrm{T} 1$ : This card game present opportunities for practice, often without the need for us to provide any questions.

T3 : When I see them playing, ... I can see that they are quite fast in zapping on the pile of cards. For example, in the relationship between five percent (5\%) and point zero five (0.05) or one-tenth (1/10) and point one (0.1) or point two five (0.25) and a quarter (1/4) ... and most of the time they were correct!

T2 : This game definitely improves their matching concepts of Fractions, decimals and percentages. Furthermore, this game also includes the use of roman numerals. Despite it not being part of the classroom syllabus, having some knowledge on this is important, and Math Zap does that.

T4 : I will say most of the players with great enthusiasm will jump for joy when they "Zapped" ... the visual speed of some students was awesome, at times faster than me..

The concept of pedagogy in its entirety has experienced massive development as of late, as far as the classroom teaching practices are concerned. Children learn best through action rather than instruction, and this leads to firsthand experience. While this form of learning through a card game is not to be viewed as a sole learning mechanism, undermining the pedagogy currently in effect, it could certainly work as a good supplemental tool to the teaching process, enhancing the engagement process between educators and learners. In essence, the vital aspects include premises such as logic, tenacity and creativity, brought about in the form of a mentally stimulating game.

$\mathrm{R} \quad$ : Does this card game enhance pedagogical practices of students' mental computation fluency in Fractions, decimals, percentages and Roman numerals, and Why?

T5 : Their mental computation has definitely improved, gathering from their action of zapping away at the pile of cards.

$\mathrm{T} 3$ : As I said earlier, this card game provides a platform for students to practice, and the more they practice, the better they get at the concept. 
$\mathrm{T} 4$ : I believe that in comparison to the formal classroom learning of fractions, decimals and percentages computation, the learning process is accelerated through Math Zap due to massive engagement and interaction amongst students.

All five teachers held the same view, namely that this game increases mental computation in terms of the ability of students to match the concepts of fractions, decimals, percentages and most importantly high alertness and visual speed. They further concluded that the students were certainly having a ball of a time. However, one teacher commented that the grouping of players based on their level of ability was important.

T3 : These players were struggling to compete with the better students and at times I noticed that they did not have the opportunity to zap... which can be demoralizing.

$\mathrm{T} 3$ : Students with lower mental computation capabilities were struggling to play with their higher ability counterparts. I believe it should be played based on similar levels of ability.

This game that involves speed does impact learners who are of different levels on the playing field. When players compete with players of higher skill levels, they tend to depict lower levels of enjoyment and engagement after game-playing. In other words, when players compete with others of equal skill levels, they tend to expend more effort and be more engaged in interaction activity than when they compete against a player of unequal skill levels.

The data from the interview among the five teachers suggest that playing the Math Zap card game was beneficial in reinforcing their prior learning in fractions, decimals and percentages. These findings echo the findings obtained by Odenweller, et al. [44] that also pointed to numerous advantages of using card games for an educational purpose by motivating students to naturally discuss the topics involved in the game; boosting the process of recalling concepts; and generally promoting learning in a healthier environment. Similarly, Beylefeld and Struwig [45] also found that the usage of card games as an informal learning methodology can scaffold the process of recalling factual knowledge. The qualitative findings also suggest that this card game has the potential to be an efficient supporting education material in reinforcing acquired skills and knowledge.

\section{DISCUSSION}

Findings from the one Group pretest-posttest experimental design depicts a mean gain of 20.41 in between the incubation period. Thus, one can conclude that the Math Zap Card Game is an effective educational game in enhancing rapid mental computation in learning fractions, decimals, percentages, whole numbers and roman numerals. In other words, playing this card game enhances quick thinking and gives rise to the ability to rapidly perform mental computations (e.g., between fractions, decimals and percentages). Alongside that, it brings about higher levels of alertness, increased mental and visual speed, and the ability to provide verbal responses. An array of research done earlier [35], [46] yielded similar findings on the usage of card games in enhancing conceptual learning amongst students.

Based on the findings, it is evident that students thoroughly enjoyed the Math Zap card game, and in the spirit of such fun, they acquired better numeracy skills. As highlighted earlier, where there is joy, fun and engagement, the better the outcome of the learning process. In fact, researchers [8], [21] have gone as far as saying that engagement as such is a pre-requisite for meaningful learning to take place, which calls for a shift in behavioural patterns of students, from being 'passive vessels' to 'active participants'. Such modes of learning, in its totality gives rise to a deeper learning experience that students can relate to. Through it, social interaction is born as well, and they are given clarity as to a specific goal. The theory behind the success of students in mental computation might be due to the development of a habitual mind, and more often than not, this happens subconsciously, without them even realizing or knowing it. The development of this habitual mind depicts the notion where learners are unaware of how they obtained the answer. For example, in a study by Parmjit [47], an interesting thought process by a student was observed ( $\mathrm{R}=\mathrm{Researcher}, \mathrm{S}=\mathrm{Student})$ :

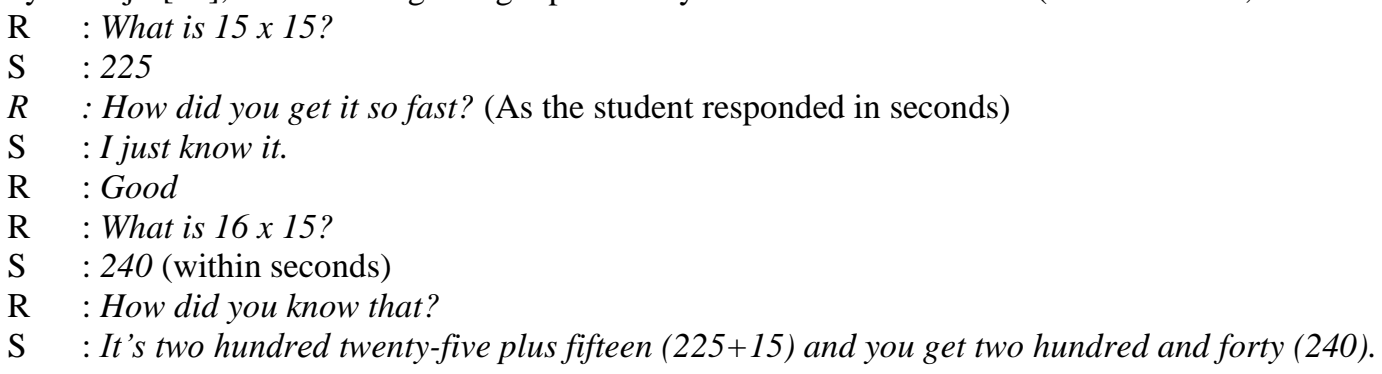


The response from the student 'I just know it' was based on his prior knowledge through iteration. Playing Math Zap cultivates the development of a routine, thereby forming a habitual mind at a fundamental level. These routines and habits are the key to consistency, which is the key to achieving goals. As the great Aristotle elucidated "We are what we do repeatedly. Excellence, then, is a habit, not an action." The findings from the intervention programs depicted that practicing mental strategies with fun and meaningful engagement had a notable effect on a students' understanding of numbers and their paradigms toward their mental strategies.

The findings of the qualitative data from the teachers' contexts suggest similar findings where all the five teachers agree that this game enhances the ability of students to perform mental computations, especially so in terms of matching the five concepts. They further concluded that students were having fun. These findings further support the quantitative finding where playing card games with student's engagement, is a pre-requisite for meaningful learning to take place which necessitates a learning change for students from being 'passive vessels' to 'active participants' [48]. In this study, the fun experienced definitely played a massive in the enhancement of scores from the pre-test to post-test. We used the term "might have" because we acknowledge the limitation of this one group quasi experimental design as stated in the methodology section. This meaningful engagement cultivated joyous learning, and this was evidential from the interviews. Among them include: 1) Students get involved; 2) Students want more; 3) Students learn first-hand. These three formed the yardstick in measuring student engagement in playing the Math Zap card game. When students experience these 'joys of learning', they reap the benefits of a productive learning session. As far as an educator is concerned, it is always a plus point when their students are self-motivated and display great hunger for knowledge, for this increases their willingness and desire to carry out the teaching process as well [49]. Thus, by understanding this, we can better appreciate why play is so important in a child's learning and development process. Making learning fun through interactive activities and games gets the children involved, wanting more and leads to firsthand experience in knowledge development. As Tree House Academy [50] puts it, "play is what pulls together the logical and creative parts of the brain."

Apart from the positives, we do acknowledge the fact that games, especially card games, have been somewhat portrayed in a negative light by some of the previous researchers, who questioned if the increase of scores might be due to some spurious factors. This view was also addressed by Amrein [51, p.14] elucidating that "Methods of gaming tests, (may) result in spurious test score gains unrelated to true gains in student learning," We are of the view that this has to do with the notion of "playing to learn" and "learning to play." The variable of play and learn in the current global context in the perspective of education compels us to question the effectiveness of playing as a process of learning. This seemed to be a dichotomy between these two variables where [52, p.1] succinctly stated that "the concept of play has been positioned in opposition to its apparently more worthwhile counterpart, work," The most potent stereotype is that learning is always seen as a formal cognitive process while playing is an informal process of emotion thus, opposite to learning. An eclectic view would note that too much learning but too little play can be tiring and too much playing may induce too little learning. Learning to play is contextualized in the situation where children play because they want to. The important observation here is that motivation in the process (be it learning or playing or both), dominantly comes inwardly within the child, and cannot be forced unto them externally by others [53], [54]. On the other hand, playing to learn resides in the context where children are made to play by the adults, in compliance with certain rules, methods and procedures. Why there are many educational games that fail to materialize for meaningful learning situations? A stance taken against games involving education is taken as depicted in "Edutainment: Is Learning at Risk?" Okan [1, p.255] states that edutainment, "involves active pedagogy and (this) totally depends on an obsessive insistence that learning is inevitably 'fun'. Is this possible due to the focus that has been on playing to learn rather than learning to play?

\section{CONCLUSION}

The findings of the study depicted that students' enjoyed playing this card game and saw improvement in terms of the development of their numeracy skills. Learner engagement through meaningful learning, enjoyment and interaction is one of the positive outcomes of this Math Zap card game based on their mental computation prowess and evaluation towards it. Consequentially, learners become more focused and are willing to dedicate a considerable amount of time to improve their performance in the game. Various findings have elucidated that engaging learners through guided play yields better outcomes in pedagogical practices as opposed to the orthodox teaching method. This is simply because the former taps on activity and exploration. In fact, coupled with proper scaffolding, this card game can stimulate cognitive interest amongst learners and thereby improving learning. Ultimately, let's not forget that we are dealing with children, beings filled with energy, ready to play at any time and place. Thus, is it not wiser to use their playful nature as a pivotal advantage in inducing the learning experience instead of brushing it aside as an obstacle? 
The authors acknowledged the limitation of one group's quasi experimental design used in the study where it lacked a comparison group that somewhat posed an inhibition on the issue of internal validity which was due to ethical and logistical constraints in the classroom environment. We therefore suggest for future researchers to use the classic experimental-control design, where the ability for causal inference can be inferred. We also suggest that future research should further explore the learning process and how students interact whilst playing card games in addition to its influences of game based learning. Finally, this study focused on mathematics in general and numeracy specifically; we would also recommend that future studies be undertaken on educational card games for subjects such as Science and English.

\section{ACKNOWLEDGEMENTS}

This work was supported by Fundamental Grant Research Scheme (FRGS) awarded by Ministry of Education Malaysian and supported by University Teknologi MARA [600-IRMI/FRGS 5/3 (211/2019)].

\section{REFERENCES}

[1] Z, Okan, "Edutainment: is learning at risk?" British Journal of Educational Technology, vol. 34, no. 3, pp. 255-264, 2003.

[2] K. S. Leung, "Why study mathematics?" 2017. [Online]. Available: https://www.fis.edu.hk/sites/default/files/uploads/NewsRelated/presentation_by_professor_leung_-_why_study_mathematics.pdf.

[3] P. Singh and N. Ellerton, "International Collaborative Studies in Mathematics Education," in M. Clements, A. Bishop, C. Keitel, J. Kilpatrick, F. Leung, Eds., Third International Handbook of Mathematics Education. Springer International Handbooks of Education. Springer, New York, 2012, pp. 827-860.

[4] T. J. Hafiz and H. A. Hina, "Causes of Poor Performance in Mathematics from the Perspective of Students, Teachers and Parents," ASRJETS, vol. 15, no. 1, pp 122-136, 2016.

[5] L. Bonne, "New Zealand Students' Mathematics-Related Beliefs and Attitudes: Recent Evidence," New Zealand Journal of Educational Studies, vol. 51, no. 1, pp. 69-82, 2016.

[6] E. Chestnut, R. Lei, S. J. Leslie, and A. Cimpian, "The myth that only brilliant people are good at math and its implications for diversity," Education Sciences, vol. 8, no. 2, p. 65, 2018.

[7] Kings College London, "Research reveals how poor maths skills are holding the UK back," 2019. [Online]. Available: https://www.kcl.ac.uk/news/research-reveals-how-poor-maths-skills-are-holding-the-uk-back.

[8] R. Gürbz and E. Erdem, "Relationship between mental computation and mathematical reasoning," Cogent Education, vol. 3, no. 1, 2018.

[9] J. LeFevre, M. Penner-Wilger, A. Pyke, T. Shanahan, and W. A. Deslauriers, "Putting Two and Two Together: Declines in Arithmetic Fluency among Young Canadian Adults, 1993 to 2005," Carleton University Cognitive Science Technical Report, 2014. [Online]. Available: https://carleton.ca/cognitivescience/wpcontent/uploads/CogSci-2014-01.pdf.

[10] L. G. Standing, "Why Johnny still can't add: Predictors of university students' performance on an elementary arithmetic task," Social Behavior and Personality an International Journal, vol. 34, no. 2, pp. 151-160, 2006.

[11] G. Mulhen and J. Wylie, "Changing levels of numeracy and other core mathematical skills among psychology undergraduates between 1992 and 2002," British Journal of Psychology, vol. 95, no. 3, pp. 355-370, 2004.

[12] S. Parmjit, et al., "From Nonsense to Number Sense: Enumeration of Numbers in Math Classroom Learning," The European Journal of Social \& Behavioural Sciences (EJSBS), vol. 25, no. 2, pp. 2933-2947, 2019.

[13] K. K. Liew, S. H. Teoh, S. E. Siti and S. Parmjit, "Learning to Make Sense of Fractions: Some Insights from the Malaysian Primary 4 Pupils," International Electronic Journal of Mathematics Education, vol. 14, no. 1, pp. 169-182, 2019.

[14] B. Harris and D. Petersen, Developing math skills in early childhood. NJ: Mathematica Policy Research, Inc., 2017.

[15] S. Toll and L. J. Van, "The developmental relationship between language and low early numeracy skills throughout kindergarten," Exceptional Children, vol. 81, no. 1, pp. 64-78, 2014.

[16] C. Aubrey and R. Godfrey, "The development of children's early numeracy through key stage 1," British Educational Research Journal, vol. 29, no. 6, pp. 821-840, 2003.

[17] P. Aunio, P. Heiskari, L. J. Van, and J. Vuorio, "The development of early numeracy skills in kindergarten in low-, average- and high-performance groups," Journal of Early Childhood Research, vol. 13, no. 1, pp. 3-16, 2015.

[18] N. Jordan, D. Kaplan, C. Ramineni, and M. Locuniak, "Early math matters: Kindergarten number competence and later mathematics outcomes," Developmental Psychology, vol. 45, no. 3, pp. 850-867, 2009.

[19] G. Burton, Number sense and operations. Reston, VA: NCTM, 1993.

[20] R. E. Reys and D. C. Yang, "Relationship between computational performance and number sense among sixth-and eighth-grade students in Taiwan," Journal for Research in Mathematics Education, vol. 29, no. 2, pp. 225-237, 1998.

[21] S. Papadakis, M. Kalogiannakis, and N. Zaranis, "The effectiveness of computer and tablet assisted intervention in early childhood students' understanding of numbers. An empirical study conducted in Greece," Educ Inf Technol, vol. 23, pp. 1849-1871, 2018

[22] K. B. Aspiranti, C. H. Skinner, D. F. McCleary, and D. F Cihak "Using Taped-Problems and Rewards to Increase Addition-Fact Fluency in a First Grade General Education Classroom,” Behavior Analysis in Practice, vol. 4, no. 2 , pp. 25-33, 2011.

[23] A. M. Heirdsfield, "Teaching mental computation strategies in early mathematics," Young Children, vol. 66, no. 2, pp. 96-102, 2011. 
[24] K. Hirsh-Pasek, et al., "Putting Education in 'Educational' Apps: Lessons from the Science of Learning," Psychological Science in the Public Interest, vol. 16, no. 1, pp. 3-34, 2015.

[25] J. P. Wen, et al., "Emerging perceptions of teacher quality and teacher development in China," International Journal of Educational Development, vol. 34, pp. 77-89, 2014.

[26] N. K. Lau, S, Parmjit, and T. Y. Hwa, "Constructing Mathematics in an Interactive Classroom Context," Educational Studies in Mathematics, vol. 72, no. 3, pp. 307-324, 2009.

[27] K. Dorjee, "Understanding of Neurolinguistics Development in Early Childhood and Its Implication to Early Child Care," LangLit An International Peer-Reviewed Open Access Journal, vol. 2, no. 1, pp. 315-326, 2016.

[28] A. McFarlane, A. Sparrowhawk, and Y. Heald, Report on the Educational Use of Games: An Exploration by TEEM of the Contribution Which Games Can Make to the Education Process. Cambridge: Teem, 2002.

[29] A. Pho and A. Dinscore, "Game-based learning," Tips and Trends: Instructional Technologies Committee, 2015.

[30] P. Rooney, and N. Whitton, Game-Based Learning and the Power of Play: Exploring Evidence, Challenges and Future Directions. Cambridge: Cambridge Scholars Publishing, 2016.

[31] K. M. Kapp, The Gamification of Learning and Instruction: Game-based Methods and Strategies for Training and Education. San Francisco: John Wiley \& Son, 2012.

[32] V. Dagiene and G. Stupuriene, "Bebras-a Sustainable Community Building Model for the Concept Based Learning of Informatics and Computational Thinking," Informatics in Education, vol. 15, no. 1, pp. 25-44, 2016.

[33] Brigham Young University, "Is video game addiction real?" 2020. ScienceDaily, [Online]. Available: https://www.sciencedaily.com/releases/2020/05/200513143803.htm.

[34] E. Hartney, "The Signs and Effects of Video Game Addiction," Verywellmind, 2020. [Online]. Available: https://www.verywellmind.com/what-is-video-game-addiction-22333.

[35] A. Gutierrez, "Development and Effectiveness of an Educational Card Game as Supplementary Material in Understanding Selected Topics in Biology," CBE Life Sci Educ, vol. 13, no. 1, pp. 76-82, 2014.

[36] R. Manzano, "The Art and Science of Teaching/Using Games to Enhance Student Achievement," Educational Leadership, vol. 67, no. 5, pp. 71-72, 2010.

[37] S. Shellenbarger, "How Family Card Games Teach Math, Memory and Self-Confidence," The Wall Street Journal, 2015. [Online]. Available: https://www.wsj.com/articles/benefits-of-a-family-card-game-1428444818.

[38] Family Education, "The Importance of playing games with your preschooler," 2017. [Online]. Available: http://goo.gl/ulk6Kg.

[39] D. W. Shaffer, K. R. Squire, R. Halverson, and J. P. Gee "Video games and the future of learning," Phi Delta Kappan, vol. 87, no. 2, pp. 104-111, 2005.

[40] M. D. Gall, J. P Gall, and W. R. Borg, Educational Research an Introduction, Third Ed. USA: Pearson Education, pp. 1-772, 1983

[41] S. A. Barab and K. Squire, "Design-Based Research: Putting a Stake in the Ground," The Journal of the Learning Sciences, vol. 13, no. 1, pp. 1-14, 2016.

[42] A. H. Schoenfeld, "Bridging the cultures of educational research and design," Educational Designer, no. 2, May 2009. [Online]. Available: http://www.educationaldesigner.org/ed/volume1/issue2/article5.

[43] A. McIntosh, R. E. Reys, and B. J. Reys, "Mental computation in the middle grades: The importance of thinking strategies," Mathematics Teaching in the Middle School, vol. 2, no. 5, pp. 322-327, 1997.

[44] C. M. Odenweller, C. T. Hsu, and S. E. DiCarlo, "Educational card games for understanding gastrointestinal physiology," The American Journal Physiology, vol. 275, no. 6, pp. 78-84, 1998.

[45] A. A. Beylefeld and M. C. Struwig, "Gaming Approach to Learning Medical Microbiology: Students' Experiences of Flow,” Journal of Medical Teacher, vol. 29, no. 9, pp. 933-940, 2007.

[46] Y. S. Tuzun, T. Karakus, Y. Inal, and G. Kizilkaya, "The effects of computer games on primary school students' achievement and motivation in geography learning," Computer and Education, vol. 52, no. 1, pp. 68-77, 2009.

[47] S. Parmjit, “An Assessment of Number Sense Among Secondary School Students," International Journal for Mathematics Teaching and Learning, pp. 1-29, 2009.

[48] K. Iverson, E-learning games: Interactive learning strategies for digital delivery. NJ: Pearson Prentice Hall, 2005.

[49] A. I. Wang, "The wear out effect of a game-based student response system," Computers \& Education, vol. 82, pp. 217-227, 2015.

[50] Tree House Academy, "The Pre-schoolers' Brain: How Young Children Learn," 2020. [Online]. Available: https://www.treehouseacademy.org/2020/01/21/the-preschoolers-brain-how-young-children-learn.

[51] B. A. Amrein, "The Unintended, Pernicious Consequences of "Staying the Course" On the United States No Child Left Behind Policy," International Journal of Education Policy \& Leadership, vol. 4, no. 6, pp. 1-13, 2009.

[52] S. Roger, Rethinking Play and Pedagogy in Early Childhood Education. Oxon: Routledge, 2011.

[53] M. K. Tokan and M. M. Imakulata, "The effect of motivation and learning behavior on student achievement," South African Journal of Education, vol. 39, no. 1, pp. 1-8, 2019.

[54] J. Sarama and D. H. Clements, "Mathematics in early childhood," Mathematics in Early Childhood Education, pp. 67-94, 2008 